\title{
Leader Spirituality and Leader Virtues as Predictors of Effective Leadership
}

\author{
Mark Green T. Ph.D. \\ Our Lady of the Lake University, San Antonio, TX \\ Carol A. Wheeler Ph.D. \\ Our Lady of the Lake University, San Antonio, TX
}

Maria N. Hodgson Ph.D.

University of Texas, Brownsville, TX

\begin{abstract}
A growing body of literature indicates that leader spirituality positively influences how leaders lead. There is also a body of literature that indicates that followers associate good leadership with behaving ethically. A concept related to leader ethics is leader virtues. Historically, virtues have been written about from a theological perspective. Recently, Riggio, Zhu, Reina \& Maroosis (2010) developed an empirical assessment to measure leadership virtues. In this study, 143 leaders were rated by their followers, peers and supervisors using the Multifactor Leadership Questionnaire and the Leadership Virtues Questionnaire. The leaders completed three spiritual and religious assessments on themselves. The results of the analysis found that leader spiritual well-being had direct effects on how virtuously and how actively followers, colleagues and supervisors rated these leaders.
\end{abstract}

Key words: spirituality, religiosity, leadership, virtues, ethics

\section{INTRODUCTION}

In a 2010 Gallup survey, 80 percent of respondents rated nurses and military officers "high" or "very high" on honesty and ethics. Only 15 percent of respondents, however, rated business executives high or very high. While there are many possible explanations for these striking differences, one obvious one is the idea that military officers and nurses follow a code of conduct that includes service to others, often above their personal needs. Business executives, on the contrary, are often seen as willing to engage in a range of questionable acts in order to increase company profits, and, at its worst, their personal annual bonuses. Respondents in the Gallup survey likely envision this group of leaders as lacking a code of conduct and strong personal virtues that emphasize things such as courage in pursuit of noble causes and justice for others.

When measuring leader ethics, Brown, Trevino and Harrison (2005) provide a widely referenced definition: "demonstration of normatively appropriate conduct through personal actions and interpersonal relationships, and the promotion of such conduct to followers through two-way communication, reinforcement, and decision-making" (p. 120). Brown's Ethical Leadership Scale is based on this definition and is often used to measure leader ethics. The Ethical Leadership Scale tends to focus on the ethical behaviors of leaders, asking questions such as (a) [the leader] disciplines employees who violate ethical standards and (b) defines success not just by results but also the way they are obtained. A related but somewhat different approach to ethics is the idea of leader virtues. The underlying premise behind a virtue is that it is something that is practiced all of the time - both professionally and personally.

An emerging instrument to measure leader virtue is the Leadership Virtues Questionnaire. This instrument asks questions such as (a) [the leader] would rather risk his/her job than do something that was unjust, (b) may have difficulty standing up for his/her beliefs among friends who do not share the same views, and (c) seems to be overly concerned with his/her personal power (Riggio et al., 2010).

Correspondence concerning this article should be addressed to Mark T. Green, Professor of Leadership Studies, Our Lady of the Lake University, 411 S. W. 24th Street, San Antonio, TX 785207. email: MTGreen@Lake.Ollusa.Edu 
A different body of literature indicates that leader spirituality is somewhat related with ratings of effective leadership (Karakas, 2010; Marques, 2010; Rozuel \& Kakabadse, 2010; Smith \& Malcolm, 2010; Bugenhagen, 2009; Fry \& Cohen, 2009; Ferguson \& Milliman, 2008). A surprisingly limited but third body of literature indicates some empirical association between leader spirituality/religiosity and leader ethics/virtue.

Figure 1.1 provides a visual representation of these limited relationships found in the empirical literature. These relationships, however, have been found in separate studies. To date, no single study has explored whether these relationships exist within the same sample.

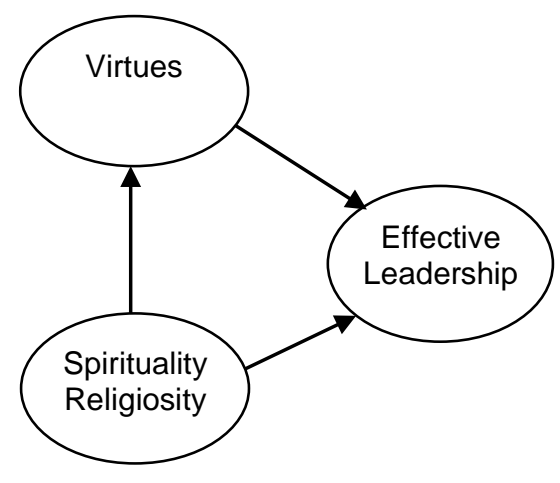

Figure 1.1: Conceptual Model A

Additionally, whether leader spirituality mediates the relationship between followers' ratings of the leaders' virtues and effective leadership has not been reported.

\section{PURPOSE OF THE STUDY}

When conducting research in the field of leadership many options exist. Some researchers, for example, perform focus group interviews or case studies. The information garnered in these types of studies is very rich. However, typically these types of studies are conducted with small samples, which limit the ability to generalize their results. Additionally, even with methods of triangulation, these types of studies tend to lack something equivalent to an alpha level for establishing significance. They are primarily very rich, but descriptive information.

Many quantitative leadership studies tend to use the survey method. Generally, these types of studies fall into one of two designs. In Leader-Only types of studies, researchers ask leaders to complete self-assessments of how they believe they lead. Demographic comparisons are often made, such as self-assessed leadership styles of women versus men. Leaders might also take a second instrument such as a personality assessment to assess the relationship between the constructs measured. For example, a researcher might explore relationships between leaders' personality scores and self-assessed leadership scores.

Leader-only types of studies suffer from the problem of leader self-perception. Any working adult has encountered at least one leader who was a megalomaniac. The followers of that particular leader believed she/he was a very poor leader. Yet, the leader's inflated sense of self would result in that leader completing a self-assessment that would indicate she/he was an extraordinary leader. To some degree, the law of large numbers eventually accounts for some of this self-assessment bias, but it will still be present in leader-only types of studies.

In an Other-Than-Leader type of study, some combination of stakeholders assesses how the leader leads. Often these raters are the leader's followers, but they can also be peers, the leader's own boss or some other stakeholder group. This type of assessment provides a more realistic assessment of how the leader actually leads than does a leader-only study (Green, Chavez, Lopez \& Gonzalez, 2012).

In this Other-Than-Leader study, 134 leaders were each rated by two followers, two peers and a supervisor on two aspects of leadership. Raters completed the Multifactor Leadership Questionnaire on the leaders in this study, as well as the Leadership Virtues Questionnaire. The leaders then completed the Spiritual Well-Being Scale, Daily Spiritual Experiences Scale and Religious Orientation Scale on themselves. Structural Equation Modeling was used to explore the relationships among all of these latent variables. 


\section{PREVIOUS STUDIES}

\section{Research on Virtues}

Although the idea of virtues has been discussed in the theological literature for millennia, the specific application of virtues to leadership as a measureable construct is relatively new. Consequently, there are only a few empirical studies of leader virtue. While not the same, a related construct is leadership ethics, for which there has been sufficient research to produce meta-analytic findings.

\section{Meta-Analytic Studies of Leadership and Ethics}

Davis and Rothstein (2006) meta-analyzed 12 studies in which followers rated the integrity of their leader/manager and, in turn, completed job satisfaction instruments. Each of the individual studies reported positive relationships between perceived leader integrity and follower outcomes. The mean corrected correlation $\left(r_{c}=.48\right)$ indicated that increased manager/leader behavioral integrity was correlated with followers who reported higher job satisfaction, higher satisfaction with the organization's leadership, and higher commitment to the organization.

Martin and Cullen (2006) meta-analyzed 42 studies that measured leader ethics and follower job satisfaction, follower psychological well-being and dysfunctional behavior. One finding was that the more followers believed the organizational climate emphasized self-interest and company profit, the less job satisfaction and the more dysfunction the followers reported. Conversely, the more followers believed the climate fostered ethical decisions that were based on an overarching concern for the well-being of others, the higher the followers rated their job satisfaction and psychological well-being. O'Fallon and Butterfield's (2005) review of 127 articles related to ethical decision-making found that, generally, establishing an ethical climate positively influenced perceptions of ethical decision-making.

\section{Transformational Leadership and Ethics}

Several studies have specifically addressed the relationship between transformational leadership and ethics. Olsen, Larsson, and Eid (2010) found a strong relationship between ratings of the leaders' ethical justice behaviors and scores from the Multifactor Leadership Questionnaire.

Toor and Ofori (2009) found strong relationships between ratings given to leaders using the Multifactor Leadership Questionnaire and ethical ratings using the Ethical Leadership Scale. Ratings of the leaders' ethicality were positively correlated with transformational leadership and negatively correlated with passiveavoidant leadership. Engelbrecht, Van Aswegen and Theron (2005) found a positive relationship between leaders' ratings using the Multifactor Leadership Questionnaire and ratings of the ethical climate as measured by Victor and Cullen's Ethical Climate Questionnaire.

Hood (2003) found a positive relationship between ratings given to leaders using the Multifactor Leadership Questionnaire and the leaders' morality-based, social, personal and competency-based values. Passive leadership style was negatively correlated to competency-based values

\section{Transformational Leadership and Virtues}

Riggio et al. (2010) found that leader assessments on the Leadership Virtues Questionnaire (LVQ) were positively related to assessments of authentic leadership, ethical leadership and transformational leadership. Scores on the LVQ were inversely correlated with the personality characteristic of narcissism. LVQ scores were also positively related with follower psychological empowerment, follower organizational identification and follower moral identity. 


\section{Summary}

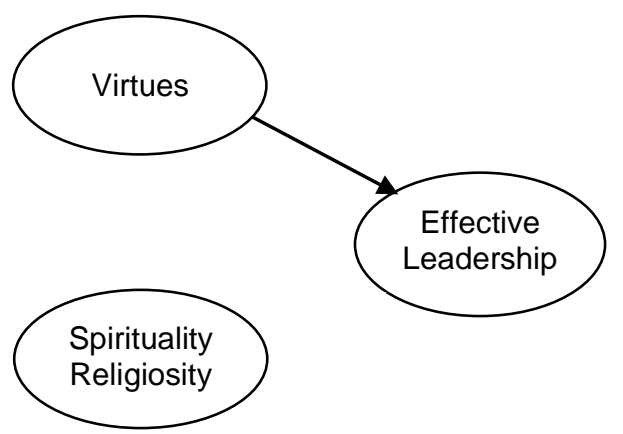

Figure 1.2 Conceptual Model B

Based on the literature, evidence does exist to support the idea that the more ethical or virtuous leaders are, the more followers view those leaders as effective.

\section{Spirituality and Leadership}

There are a variety of well-conceived articles that advance models of spiritual leadership or posit that spiritual leadership can have positive impacts in organizations. (See, for example, Karakas, 2010; Marques, 2010; Rozuel \& Kakabadse, 2010; Smith \& Malcolm, 2010; Bugenhagen, 2009; Fry \& Cohen, 2009; Ferguson \& Milliman, 2008). While these types of expository articles assist in rich dialogue about spiritual leadership, there is a lack of empirical evidence to support the various models and theories they present. There are, however, several empirical studies related to leader spirituality. Generally this body of literature indicates that leader spirituality is related to positive organizational outcomes such as culture and follower opinions.

Green, Kodatt and Duncan (2011) analyzed the relationship between ratings of leaders' transformational leadership done by followers and leader self-assessed spirituality. The higher leaders scored on existential spiritual well-being and extrinsic religiosity, the more followers rated the leaders as transformational.

Reave (2005) reviewed over 150 studies that she loosely linked to spirituality. Reave used the independent variables of integrity, honesty, humility, respect for others, fairness, expressing caring and concern, listening responsively, appreciating others, and taking time for personal reflection as examples of spiritual values. She found that these leadership values are often related to outcomes such as organizational success and follower motivation. While these values are likely found in most leaders who are spiritual or religious, they are also seen in almost every popular leadership theory, such as the full-range of leadership, servant leadership, Project GLOBE and forth. The degree to which these values are exclusive to "spiritual leadership" rather than simply "good leadership" is easily debated.

Sanders, Hopkins and Geroy (2003) collected data on follower spirituality, follower job commitment and leader spirituality using structural equation modelling. The researchers found that spiritual leadership was related to follower spirituality which was in turn related to employee commitment. Karadağ (2009) asked over 4,500 teachers to rate their leaders' spirituality using The Spiritual Leadership Scale and to rate their organizational culture using the Organizational Culture Scale. Using structural equation modelling, spiritual leadership behaviors positively affected organizational culture. Duchon and Plowman (2005) administered the Meaning and Purpose of Work questionnaire to both workers and leaders in five emergency room/intensive care units and one medical/surgery unit. After controlling for leader and follower demographics, spirituality scores for supervisors in the top performing units were higher than those of the lower performing units.

Two studies have reported results from designs in which leaders completed spirituality instruments on themselves as well as instruments that measure how they believe they lead. Hartsfield (2003) administered the Multifactor Leadership Questionnaire and the Spiritual Well-Being Scale to 124 leaders from a large aerospace company and found a positive relationship between leader spirituality and self-reported leader transformational leadership. Twigg and Parayitam (2007) surveyed 186 participants who were members of the Academy of Management. The respondents' self-assessed spirituality scores were also positively correlated with their self-assessed transformational leadership scores. 


\section{Summary}

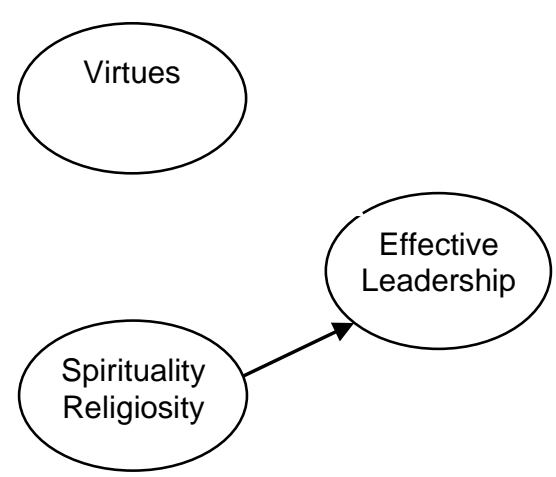

Figure 1.3: Conceptual Model C

Based on the literature, evidence exists to support the idea that the more spiritual leaders are, the more followers view those leaders as effective.

\section{Religiosity and Ethics}

Burton, Tulpade and Hayes (2011) examined the relationship between overall value systems as reflected in religiosity or participation in religious activities and academic dishonesty. A large majority of the students (86\%) had engaged in some form of unethical test-taking behaviors at some point in their college careers. A high percentage (72\%) also indicated they had participated in religious activities at least once every quarter. Overall, results gave some positive indications, showing that students who were more 'religious' and participated more in religious activities were significantly less likely to engage in unethical test taking practices.

In another study, Barnett (1996) found that students who were less likely to cheat were more intrinsically religious and were more likely to report a peer's wrongdoing than religious students. Knotts, Lopez, Burnthorne and Mesak (2000), examined a sample of 216 undergraduate business students to determine the impact of religiosity in general, and the type of religious practice on ethical judgment. The results indicated that more intrinsically religious students were more likely to view questionable business actions as unethical compared to less religious students.

In a study conducted by Rafikz (2006), 131 undergraduate students completed an end-of-course survey. The results indicated that religiosity was a significant determinant of ethical determination and likely behavior. More religiously-committed students were more likely to view questionable actions as unethical compared to less religiously-committed students.

A study by Al-Kahtani (2008) investigated the influence of education and income and religiosity on the ethical philosophy of students. Students with high religious orientation reported higher scores on ethical philosophy measures than did students with low religious orientation.

\section{Ethics and Spirituality}

In a study of 260 advertising CEOs in Thailand, Phattanacheewapul and Ussahawanitchakit (2009) found a relationship between spirituality and ethics. This study considered spirituality and ethics from an organizational perspective. They defined Organizational Spirituality Mindset (OSM) as a combination of four variables: Career Obligation, Success Concentration, Sense of Ownership, and Tasks Perseverance. Regression analysis found that virtue ethics had an impact on each of the four dimensions of OSM. The authors concluded that firms with stronger virtue ethics will not only display greater organizational spirituality, but will likely be more successful. 


\section{Summary}

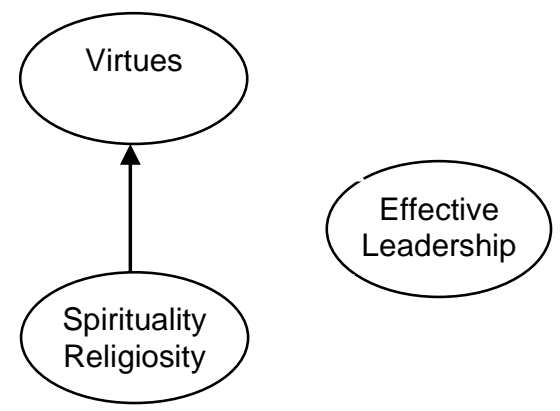

Figure 1.4: Conceptual Model D

Based on the literature, very limited evidence exists to support the idea that the more spiritual or religious leaders are, the higher their scores on measures of ethics or virtues.

\section{INSTRUMENTS}

The Multifactor Leadership Questionnaire (MLQ) was developed to determine the degree to which leaders exhibited transformational and transactional leadership. The MLQ has a significant place in the empirical research literature, after extensive validation with many extension studies. The Form $5 X$ contains five transformational leadership subscales, two transactional subscales, and two passive subscales of leadership that together form what is known as the full range leadership theory. The full range leadership model represented by the MLQ 5X had a goodness of fit (GFI) of .91 and the root mean squared residual (RMSR) was .04. Each was above and below their perspective cut-off criterion respectively.

The Leadership Virtues Questionnaire (Riggio et al, 2010) measures four leader virtues: (1) prudence, (2) fortitude, (3) temperance and (4) justice. Prudence is the wisdom that manages or dictates a proper balance between two extremes in a world of shifting contexts and priorities. It is often associated with knowledge, practical wisdom, and insight. Fortitude includes the characteristics of perseverance, patience, endurance and courage directed toward adversity on behalf of a noble cause. Temperance is the ability to control one's emotions by accepting her/his deficiencies. Justice is a sustained or constant willingness to give others what they deserve. The LVQ was developed through four successive pilot tests representing over 1,000 managers. Both exploratory and confirmatory factor analyses were used to develop the 19 questions used in the questionnaire. The instrument is strongly positively correlated with relevant measures of authentic leadership $(r=.90, p=.01)$, ethical leadership $(r=.93, p=.01)$, and transformational leadership $(r=.85, p=.01)$

The Spiritual Well-Being Scale (Paloutzian \& Ellison, 1982) is a 20-item instrument composed of two subscales of 10 items each. The Religious Well-Being (RWB) subscale assesses the degree to which individuals report that they experience a satisfying relationship with God. Items of the Existential Well-Being (EWB) subscale relate to a sense of life satisfaction and purpose. The scale is not based on a specific religious or ideological orientation. In addition, the scales have demonstrated good internal consistency and construct validity (Bufford, Paloutzian, \& Ellison, 1991; Ellison, 1983; Ellison \& Smith, 1991).

The Daily Spiritual Experiences Scale "is intended to measure a person's perception of the transcendent (God, the divine) in daily life and his or her perception of his or her interaction with or involvement of the transcendent in life. The items attempt to measure experience rather than particular beliefs or behaviors" (Underwood \& Teresi, 2002, p. 23). Evidence of construct validity was developed through in-depth interviews and focus groups with individuals from many religious perspectives. The authors also conducted a review of scales that attempt to measure some aspects of spiritual experience and drew as well on a variety of theological, spiritual, and religious writings provided by examination of correlations of the DSES with health and quality of life variables (Underwood \& Teresi, 2002).

The Allport-Ross Religious Orientation Scale (ROS) distinguishes intrinsically religious people who are genuinely committed to their faith from the more self-serving extrinsically religious (Allport \& Ross, 1967). "Extrinsic religiousness was considered to be instrumental in nature, described as immature and utilitarian, whereby a person uses his/her religiousness to achieve extra-religious (psychological and social) ends" (Flere and Lavrič, 2008, p. 521; Allport \& Ross, 1967, p. 434, Miller, D. \& Ewest, T., 2011). 
In contrast, Intrinsic Religious Orientation sees religion, or devotion as the end, "the motive for religiousness would be autonomous and over-reaching" (Flere and Lavrič, 2008, p. 521, Miller, D. \& Ewest, T., 2011). The intrinsically oriented individual is "motivated by their religion to live their religion and in this living fulfill their commitment to their faith and jointly fulfilling their duty to those around them." (Hill \& Hood, 1999, p. 119).

\section{PARTICIPANTS}

The participants in this study were 143 working adult leaders from the southern part of the United States who were about to begin leadership training. As part of a baseline assessment prior to the training the leaders asked two followers, two peers and their supervisor to rate them through Survey Monkey on the Multifactor Leadership Questionnaire and Leadership Virtues Questionnaire. Prior to the onset of training, the leaders completed the three spirituality/religiosity instruments on themselves.

There were 93 female and 50 male leaders in the study. Twenty-four leaders were white, 41 were black and 78 were Hispanic. Ages ranged from 25 to 54 with a mean age of 39. Fifty-four leaders held Bachelors degrees and 89 held Masters degrees. Most of the leaders described themselves as mid-level in their organizations.

\section{RESULTS}

\section{Initial Exploratory Factor Analysis}

Figure 1.1 (above) assumes that the instruments used in this study are measuring three separate constructs: virtues, spirituality/religiosity and effective leadership. Because 18 scales from five separate instruments were used in this study, a first analysis performed was an exploratory factor analysis using the principle components method with Varimax rotation.

Table 1 provides the results of this analysis. Five components were found with an Eigenvalue greater than 1.0. The first component, labeled Effective Leadership, consisted of the first six scales of the Multifactor Leadership Questionnaire that loaded with an Eigenvector score greater than .50. The second component found consisted of the four scores from the Leadership Virtues Questionnaire. The third component consisted of the intrinsic score from the Religious Orientation Scale and the overall score from the Daily Spiritual Experiences Scale. The fourth component consisted of the scores from the Spiritual Well-Being Scale. The final component consisted of the three scores from the Multifactor Leadership Questionnaire considered least effective.

Table 1: Rotated Exploratory Factor Analysis

\begin{tabular}{lrrrrr}
\hline & $\begin{array}{r}\text { Effective } \\
\text { Leadership }\end{array}$ & $\begin{array}{r}\text { Leader } \\
\text { Virtues }\end{array}$ & $\begin{array}{r}\text { Religious } \\
\text { Spirituality }\end{array}$ & $\begin{array}{c}\text { Spirituality } \\
\text { Ineffective } \\
\text { Leadership }\end{array}$ \\
\hline Idealized Influence A & $\mathbf{0 . 6 9}$ & 0.32 & -0.05 & -0.21 & -0.09 \\
Idealized Influence B & $\mathbf{0 . 8 0}$ & -0.03 & 0.06 & 0.06 & -0.10 \\
Inspirational Motivation & $\mathbf{0 . 8 5}$ & 0.23 & 0.07 & 0.07 & -0.11 \\
Intellectual Stimulation & $\mathbf{0 . 8 4}$ & 0.12 & -0.02 & 0.00 & -0.07 \\
Individual Consideration & $\mathbf{0 . 7 8}$ & 0.35 & -0.03 & 0.02 & -0.07 \\
Contingent Reward & $\mathbf{0 . 5 0}$ & 0.41 & 0.02 & 0.27 & 0.32 \\
\hline Prudence & 0.28 & $\mathbf{0 . 8 5}$ & 0.03 & 0.13 & -0.08 \\
Fortitude & 0.22 & $\mathbf{0 . 7 6}$ & 0.18 & 0.08 & -0.06 \\
Temperance & 0.04 & $\mathbf{0 . 7 3}$ & -0.23 & 0.15 & -0.02 \\
Justice & 0.18 & $\mathbf{0 . 9 0}$ & -0.05 & 0.07 & 0.07 \\
\hline Internal Religious Orientation & -0.09 & -0.15 & $\mathbf{0 . 8 8}$ & 0.03 & 0.10 \\
Daily Spiritual Experiences & -0.07 & -0.07 & $\mathbf{0 . 8 7}$ & 0.24 & 0.08 \\
\hline Spiritual Well-Being Religious & -0.07 & 0.25 & 0.44 & $\mathbf{0 . 7 8}$ & 0.06 \\
Spiritual Well-Being Existential & 0.08 & 0.17 & 0.04 & $\mathbf{0 . 9 4}$ & 0.00 \\
\hline MBE Active & 0.42 & 0.03 & 0.17 & -0.05 & $\mathbf{0 . 6 7}$ \\
MBE Passive & -0.40 & 0.05 & -0.11 & 0.19 & $\mathbf{0 . 7 7}$ \\
Laissez Faire & -0.36 & -0.14 & 0.00 & -0.06 & $\mathbf{0 . 6 7}$ \\
\hline External Religious Orientation & -0.21 & -0.11 & -0.34 & -0.02 & 0.12 \\
\hline & 41 & & &
\end{tabular}




\section{Confirmatory Factor Analysis}

The exploratory factor analysis identified five latent variables from the 18 scales used in this study: Effective Leadership, Leader Virtues, Religious Spirituality, Spirituality and Ineffective Leadership. Three of the latent variables - Religious Spirituality, Spirituality and Ineffective Leadership - consist of either two or three observed variables. These types of latent variables are often classified as under-defined. Two of the latent variables, however, consisted of four or more observed variables. For those two latent variables, additional confirmatory factor analysis was performed. The six observed variables comprising Effective Leadership had a Goodness of Fit Index of .98 and a Root Mean Square Residual of .01. Both measures indicated the observed variables fit the latent variable quite well. The four observed variables of the Leadership Virtues Questionnaire also fit the theorized model well with a Goodness of Fit Index of .99 and a Root Mean Square Residual of .00.

\section{Inter-Correlations among Latent Variables}

The second analysis performed was to analyze the inter-correlations among the latent variables of Effective Leadership, Spirituality, Leader Virtues, Religious Spirituality, and Ineffective Leadership using structural equation modeling. Figure 2 and Table 2 provide the results of that analysis.

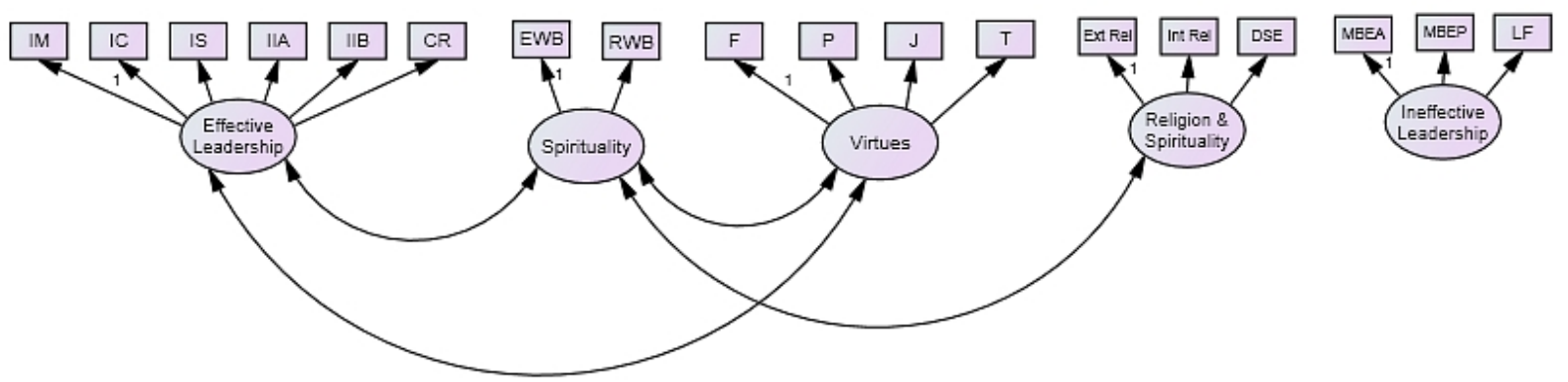

Figure 2: Significant relationships among latent variables

Table 2: Results of Structural Equation Model

\begin{tabular}{|c|c|c|c|c|c|c|}
\hline Variable & & Variable & S.E. & C.R. & P. & Correlation \\
\hline \multicolumn{7}{|c|}{ Significant relationships } \\
\hline Effective L. & $<-->$ & Virtues & 0.01 & 4.33 & 0.00 & 0.50 \\
\hline Spirituality & $<-->$ & $\mathrm{Rel} / \mathrm{Sp}$ & 3.39 & 2.96 & 0.00 & 0.27 \\
\hline Virtues & $<-->$ & Spirituality & 0.20 & 2.28 & 0.02 & 0.22 \\
\hline Effective L. & $<-->$ & Spirituality & 0.20 & 1.79 & 0.07 & 0.15 \\
\hline \multicolumn{7}{|c|}{ Non-significant relationships } \\
\hline Effective L. & $<-->$ & $\mathrm{Rel} / \mathrm{Sp}$ & 0.12 & -1.37 & 0.17 & -0.11 \\
\hline Spirituality & $<-->$ & $\mathrm{Rel} / \mathrm{SP}$ & 0.12 & -1.03 & 0.30 & -0.09 \\
\hline ATFL & $<-->$ & $\mathrm{MBE} / \mathrm{LF}$ & 0.01 & -0.43 & 0.67 & -0.39 \\
\hline MBE/LF & $<-->$ & Virtues & 0.00 & -0.42 & 0.67 & -0.23 \\
\hline MBE/LF & $<-->$ & $\mathrm{Rel} / \mathrm{Sp}$ & 0.03 & 0.41 & 0.68 & 0.14 \\
\hline MBE/LF & $<-->$ & Spirituality & 0.02 & -0.18 & 0.86 & -0.02 \\
\hline
\end{tabular}

\section{Direct and Indirect Effects}

Whereas the results shown in Figure 2 described two-way or correlational relationships among the latent variables, Figure 3 provides the results of predictive relationships obtained through multiple regression. The 
leaders' spirituality influences the ratings they received from followers, peers and supervisors on both leadership virtues $\left(R^{2}=.05, B=.23, p=.00\right)$ and effective leadership $\left(R^{2}=.09, B=.26, p=.00\right)$. Virtues also had an influence on ratings of effective leadership $\left(R^{2}=.28, B=.48, p=.00\right)$.

It is tempting to make the assumption shown in Figure 4 that spirituality influences virtues which influences effective leadership. An additional analysis was conducted to analyze whether this was true. A mediated regression tested whether leader virtues mediated the relationship between spirituality and effective leadership and it did not. The jump from Figure 3 to Figure 4 is not supported.

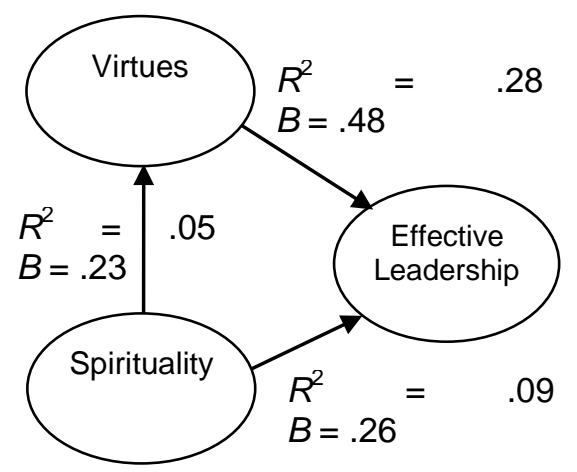

Figure 3: Relationships obtained through regression analysis

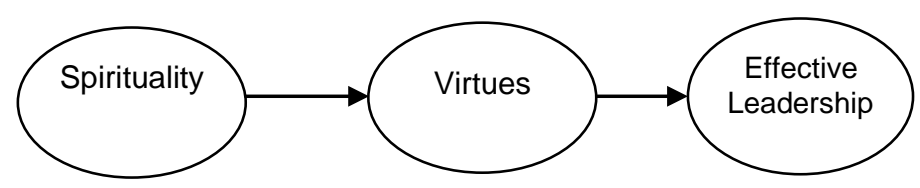

Figure 4: Fully mediated relationship not found

\section{DISCUSSION}

\section{Correlates of Active Leadership}

The 360-degree ratings on active leadership (the transformational and contingent reward scales from the MLQ) given to the leaders in the study were positively related to the ratings of leader virtue given to those leaders.

Spirituality, measured by the Spiritual Well-Being Scale, was also positively correlated with 360-degree ratings of active leadership. The more the leaders in this study indicated they were spiritual, the more followers, peers and supervisors believed those leaders demonstrated effective leadership.

\section{Correlates of Spirituality}

In addition to the correlation between effective leadership, both religious spirituality and leadership virtues were positively correlated to spirituality. The exploratory factor analysis indicated that spiritual wellbeing and religious spirituality seem to be measuring separate constructs. Their positive correlation, however, was not surprising.

\section{Implications for Leadership}

The results of this study indicate that both virtuosity and spirituality can predict effective leadership. However, they seem to be operating separately. That is, while either one separately contributes to effective leadership, there is no combined effect. Further, virtuosity is a stronger influence on effective leadership than spirituality. One possible reason for this is that it is easier for leaders to demonstrate virtuosity in the workplace than spirituality. We want our leaders to be good, upstanding citizens, and therefore look for virtuosity. Spirituality is more often considered a private matter, best left out of the workplace. Not only does a typical work environment make it easier to demonstrate virtuosity, it likely encourages such demonstration 
to a much greater degree than it encourages the demonstration of spirituality. Virtuosity (particularly as measured by the LVQ) is also clearly behavioral. Followers can observe specific behaviors that contribute to a perception of virtuosity. Spirituality is much more private and reflective, and can be difficult to determine by observing the behaviors of the leader.

A great benefit of the behavioral aspect of virtuosity is that it is something that leaders can choose to focus on; it can be learned and practiced. This gives leaders an additional avenue to consider when trying to increase their effective leadership in the workplace. Some specific examples of workplace behaviors related to each of the four virtues from the Leadership Virtues Questionnaire are found in Table 3.

Table 3: Example Behaviors of Leader Virtues

\begin{tabular}{ll}
\hline Virtue & Possible Leader Behaviors \\
\hline Prudence & Demonstrate a balance between the need for profit and the needs of followers \\
Temperance & Control emotions by not overreacting in positive or negative situations \\
Justice & $\begin{array}{l}\text { Be a good role model, demonstrate fairness and consistency in relationships with } \\
\text { employees } \\
\text { Fortitude }\end{array}$ \\
& $\begin{array}{l}\text { Share the causes that motivate you, demonstrate that you make decisions based on a } \\
\text { noble cause rather than just the bottom line }\end{array}$ \\
\hline
\end{tabular}

In addition to the leader working on behaviors associated with virtuosity, this established relationship between virtuosity and effective leadership provides a unique opportunity for self-reflection. Considering past experiences and how a leader might change those in the future is an established personal development method that can be particularly useful. As leaders consider past events related to the four areas of virtue, they will have an opportunity to determine how they would do things differently in the future. This is also an excellent way to incorporate spirituality back into leader development. Although this study did not show spirituality as a mediating variable between virtue and active leadership, it did show that spirituality had a direct effect on both virtue and active leadership. Spirituality still plays a role in both, and it is reasonable to believe that this effect could be magnified through self-reflection. Table 4 provides some possible reflection questions related to each of the four areas of virtue.

Table 4: Possible Reflection Questions

\begin{tabular}{ll}
\hline Virtue & Sample Reflection Questions for Leader Development \\
\hline Prudence & Talk about a time you were able to effectively balance two extremes, such as pleasing \\
your boss on one hand and pleasing employees on the other. & What was it that allowed you to do this so well? How did your spirituality play a role? \\
Temperance & In the workplace, what are examples of behaviors that trigger an emotional reaction \\
(positive or negative) from you? In other words, what are your hot buttons? Why do \\
you think these things trigger a strong reaction? \\
Think about a time you demonstrated emotional control and did not react strongly. \\
What specific thoughts and behaviors allowed you to do this? \\
How can your personal spirituality help with this type of emotional control? \\
Justice \\
Think about a situation when it was difficult to decide how to treat two people fairly. \\
How did your spirituality play a role in your final decision? \\
Think about a leader you thought was very fair - try to identify specific behaviors she \\
exhibited that make you believe this. \\
Think about a time you fought tirelessly to right an injustice. What behaviors did you \\
exhibit? What was your frame of mind? How did your personal spirituality influence \\
your behavior? \\
Think about a time in which you were a victim - what would you have wanted a \\
leader to do for you in this situation?
\end{tabular}




\section{CONCLUSION}

This study found that leader spirituality, leader virtue, and effective leadership are all interrelated. This is exciting for two reasons. First, it points to the possibility that being a virtuous, spiritual person leads to being an effective leader. It also gives leadership scholars and religious leaders alike tools to help people develop their leadership capacity through developing their own spirituality and virtuous behaviors. Further studies should consider these concepts in other groups of people, and also look specifically at what developmental processes can contribute to a leader's growth in all three key areas of spirituality, virtue and active leadership.

Dr Mark Green is a Professor of Leadership Studies at Our Lady of the Lake University in the United States. He holds a PhD in Educational Administration, MBA, MS in Information Systems, MEd, and MA in Theology. He teaches leadership in his university's doctoral program in leadership studies, and has chaired over 40 doctoral dissertations in the field of leadership. Prior to his career in academe, he served as a US military officer with assignments that included the Pentagon and the Army Medical Department Center.

Dr Maria Saldivar Hodgson is an Assistant Professor of Communication Studies and is also the Director of the Center for Civic Engagement at The University of Texas at Brownsville. She holds a PhD in Leadership Studies and MA in Communication Studies with a concentration in Organizational Communication. She is an active member of numerous departmental and university committees. Saldivar Hodgson serves on the board of directors for state and community charitable organizations and provides leadership and communication training to various organizations.

Dr Carol Wheeler is an Assistant Professor in the Leadership Studies department at Our Lady of the Lake University in San Antonio, Texas. She holds a PhD in Leadership Education from Oklahoma State University, MS in Higher Education and Student Affairs from Indiana University and BS in Agricultural Leadership Development from Texas A\&M University. Carol is passionate about helping students learn more about themselves and about leadership as theory and practice. Her research interests include crisis leadership, emotional concepts in the practice of leadership, and how students and professionals learn and practice leadership.

\section{REFERENCES}

Al-Kahtani, A. S., (2008). Ethical Values of Graduate and Undergraduate Business Students in Saudi Public Universities. Review of Business Research, 8 (6).

Allport, G.W. \& Ross, J.M. (1967). Religious orientation and prejudice. Journal of Personality and Social Psychology, 5, 432-443.

Barnett, T., Bass, K \& Brown, J., (1996). Religiosity, Ethical Ideology and Intentions to Report a Peer's Wrongdoing. Journal of Business Ethics, 15.

Bass, B. M. \& Avolio, B. (2000). Manual for the Multifactor Leadership Questionnaire, technical report for MLQ Form $5 X$-short. ( $2^{\text {nd }}$ ed). Redwood City, CA: Mindgarden Publishers Inc.

Brown, M.E., Treviño, L.K. \& Harrison, D.A., (2005). Ethical Leadership: A Social Learning Perspective for Construct Development and Testing. Organizational Behavior and Human Decision Processes, 97, 117-134.

Bufford, R. K., Paloutzian, R. F. \& Ellison, C. W. (1991). Norms for the Spiritual Well-Being Scale. Journal of Psychology and Theology, 19, 56-70.

Bugenhagen, M. J., (2009). Spirituality and Leadership: Engaging both in higher education. Journal of Leadership Studies, 3 (3), 69-74.

Burton, J.H., Talpade, S. \& Hayes, J., (2011). Religiosity and Test Taking Ethics among Business School Students. Journal of Academic and Business Ethics, 4.

Davis, A. \& Rothstein, H. R. (2006). The effects of the perceived behavioral integrity of managers on employee attitudes. Journal of Business Ethics, 67, 407-419.

Donahue, M. J. (1985). Intrinsic and extrinsic religiousness: Review and meta-analysis. Journal of Personality and Social Psychology, 48, 400-419. 
Duchon, D. \& Plowman, D.A., (2005). Nurturing the spirit at work: Impact on work unit performance. The Leadership Quarterly, 16 (5), 807.

Ellison, C. W. (1983). Spiritual well-being: Conceptualization and measurement. Journal of Psychology and Theology, 11, 330-340.

Ellison, C. W. \& Smith, J. (1991). Toward an integrative measure of health and well-being. Journal of Psychology and Theology, 19, 35-48.

Engelbrechet, A., Van Aswegen, A.S. \& Theron, C.C. (2005). The effect of ethical values on transformational leadership and ethical climate in organizations. South African Journal of Business Management, 36(2), $19-27$.

Ferguson, J. \& Milliman, J. (2008). Creating effective core organizational values: A spiritual leadership approach. International Journal of Public Administration, 31, 439-459.

Flere, S., \& Lavrič, M. (January 01, 2008). Is intrinsic religious orientation a culturally specific American Protestant concept?: The fusion of intrinsic and extrinsic religious orientation among non-Protestants. European Journal of Social Psychology, 38, 521-530.

Fry, L. W. \& Cohen, M. P. (2009). Spiritual leadership as a paradigm for organizational transformation and recovery from extended work cultures. Journal of Business Ethics, 84, 265-278.

Gallop Organization, Nurses Top Honesty and Ethics List for 11th Year, Retrieved from http://www.gallup.com/poll/145043/nurses-top-honesty-ethics-list-11-year.aspx.

Genia, V. (1993). A psychometric evaluation of the Allport-Ross I/E scales in a religiously heterogeneous sample. Journal for the Scientific Study of Religion, 32(3), 284-290.

Green, M., Chavez, E., Lopez , D. \& Gonzalez, F., (2012). The Impact of Education, Gender, Age and Leadership Experience on Preferences in Leadership, Journal of Business \& Leadership, 102-115.

Green, M.T., Kodatt, S.A. \& Duncan, P. (2011). The relationship between follower ratings of leadership and leaders' spirituality. Journal of Spirituality, Leadership and Management, 5, 46-57.

Gorsuch, R. L. \& McPherson, S. E. (1989). Intrinsic/extrinsic measurement: I/E revised and single item scales. Journal for the Scientific Study of Religion, 28, 348-354.

Hartsfield, M. (2003). The internal dynamics of transformational leadership: Effects of spirituality, emotional intelligence, and self-efficacy. Dissertation Abstracts International (UMI No. 3090425)

Hill, P. C. \& Hood, R. W. (1999). Measures of religiosity. Birmingham, AL: Religious Education Press.

Hodge, D. R. (2006). Do conceptualizations of spirituality and religion affect perceptions of compliance with the ethical standards that address religion? An exploratory study. Journal of Religion \& Spirituality in Social Work, 25(2), 1-18.

Hood, J.N. (2003). The relationship of leadership style and CEO values to ethical practices in organizations. Journal of Business Ethics, 43(4), 263-273.

Karadag, E. (2009). Spiritual Leadership and Organizational Culture: A Study of Structural Equation Modeling. Educational Science, 9(3), 1391-1405.

Karakas, F. (2010). Exploring value compasses of leaders in organizations: introducing nine spiritual anchors. Journal of Business Ethics, 94 (1), 89-106.

Kirkpatrick, L. A. (1989). A psychometric analysis of the Allport-Ross and Feagin measures of intrinsic-extrinsic religious orientation. In M. L. Lynn \& D. O. Moberg (Eds.), Research in the social scientific study of religion: Vol. 1. Greenwich, CT: JAI Press.

Knotts, T.L., Lopez, T., Burnthorne \& Mesak, H.I. (2000). Ethical Judgments of College Students: An Empirical Analysis, Journal of Education for Business, 75 (3), 158.

Leong, F. T. \& Zachar, P. (1990). An evaluation of Allport's Religious Orientation Scale across one Australian and two United States samples. Educational and Psychological Measurement, 50, 359-368.

Marques, J.H. (2010). Awakened leaders: born or made? Leadership \& Organization Development Journal, 31 (4), 307-323. 
Martin, K. \& Cullen, J. (2006). Continuities and Extensions of Ethical Climate Theory: A Meta-Analytic Review. Journal of Business Ethics, 69(2), 175-194.

Miller, D. \& Ewest, T. (2011) The Present State of Workplace Spirituality: A literature review considering context, theory, and measurement/assessment. Paper presented at the Academy of Management Annual Meeting, San Antonio, Texas, USA, August 12-16, 2011.

O' Fallon, M. \& Butterfield, K. (2005). A review of the Empirical Ethical Decision-Making Literature: 1996-2003. Journal of Business Ethics, 59, 375-413.

Olsen, O.K., Eid, J. \& Larsson, G. (2010). Leadership and ethical justice behavior in high moral intensity operational context, Military Psychology, 22, 137-156.

Paloutzian, R.F. \& Ellison, C.W. (1982). Loneliness, spiritual well-being and quality of life. In L. A. Peplau \& D. Perlman (Eds.), Loneliness: A sourcebook of current theory, research and therapy (pp. 224-237). New York: Wiley Interscience.

Phattanacheewapul, A. \& Ussahawanitchakit, P. (2009). Creating organizational spirituality mindset of advertising agencies in Thailand: Effects on business success through intrinsic work satisfaction, openness to changefulness and self benevolence. International Journal of Business Research, 10(1), 67-89.

Rafikz, E. (2006). The Impact of Locus of Control and Religiosity on Auditing Students' Ethical Reasoning. Culture and Religion Review Journal.

Reave, L. (2005). Spiritual values and practices related to leadership effectiveness. The Leadership Quarterly, 16(5), 655-687.

Riggio, R. (2010). Before Emotional Intelligence: Research on Nonverbal, Emotional, and Social Competences. Industrial and Organizational Psychology, 3(2), 178-182.

Riggio, R. E., Zhu, W., Reina, C. \& Maroosis, J. A. (January 01, 2010). Virtue-Based Measurement of Ethical Leadership: The Leadership Virtues Questionnaire. Consulting Psychology Journal, 62(4), 235-250.

Rozuel, C. \& Kakabadse, N. (2010). Ethics, spirituality and self: managerial perspective and leadership implications, Business Ethics, 19(40), 423-436.

Sanders, J., Hopkins, W. \& Geroy, G. (2003). From Transactional to Transcendental: Toward an Integrated Theory of Leadership. Journal of Leadership and Organizational Studies, 9(4), 21-31.

Smith, J. \& Malcolm, A. (2010). Spirituality, leadership and values in the NHS, International Journal of Leadership in Public Services, 6(2), 39-53.

Toor, S. \& Ofori, G. (2009). Ethical Leadership: Examining the Relationships with Full Range Leadership Model Employee Outcomes, and Organizational Culture. Journal of Business Ethics, 90(4), 533-547.

Twigg, N. \& Parayitam, S. (2007). Spirituality as a Determinant of Transformational Leadership: Moderating Effects of Religious Orientation. Journal of Management, Spirituality, and Religion, 4(3), 326-354.

Underwood, L. G. \& Teresi, J. (2002). The daily experience scale: Development, theoretical description, reliability, exploratory factor analysis, and preliminary construct validity using health related data. Annals of Behavioral Medicine, 24(1), 22-33. 